\title{
RENCANA PENATAAN AREA FASILITAS PENUNJANG YANG BERORIENTASI PADA AKTIVITAS BANDAR UDARA
}

\author{
Rudi Suhardi ${ }^{1)}$, Parino Rahardjo ${ }^{21}$, Sylvie Wirawati ${ }^{3)}$ \\ 1)Program Studi S1 PWK, Fakultas Teknik, Universitas Tarumangara, rudisuhardi18@gmail.com \\ 2)Program Studi S1 PWK, Fakultas Teknik, Universitas Tarumangara, parinor19@gmail.com \\ 3)Program Studi S1 PWK, Fakultas Teknik, Universitas Tarumangara, sylvie.wirawati@gmail.com
}

\begin{abstract}
Abstrak
Bandara Soekarno Hatta adalah salah satu Bandara International Indonesia yang terletak di Kota Tangerang dengan peringkat 20 besar tersibuk sejak tahun 2010 hingga 2017 di dunia, area fasilitas penunjang aktivitas Bandara Soekarno Hatta yang ditetapkan pada Rencana Tata Ruang Wilayah Kota Tangerang dan Rencana Detail Tata Ruang Bagian Wilayah Perkotaan Bandara. Area fasilitas penunjang bandar udara adalah area yang memiliki fasilitas-fasilitas yang secara langsung dan tidak langsung menunjang kegiatan bandar udara, seperti fasilitas perbengkelan pesawat udara, pergudangan, olah raga, penginapan, toko, restoran, lapangan golf, ruang terbuka hijau, perparkiran, rekreasi, dan perkantoran. Namun Area yang telah ditetapkan sebagai fasilitas penunjang tidak berfungsi dengan seharusnya dan maksimal, sehingga perlu dilakukan penataan kembali agar bisa berfungsi dengan semestinya. Penulis menggunakan 5 metode analisis, yaitu analisis kebijakan, best practice, lokasi \& tapak, pasar, dan kebutuhan ruang untuk menghasilkan usulan rencana penataan area fasilitas penunjang Bandara Soekarno Hatta dengan pendekatan Airport Oriented Activities.
\end{abstract}

Kata kunci: Aktivitas Bandara; Area Fasilitas Penunjang; Bandar Udara; Rencana Penataan

\begin{abstract}
Soekarno-Hatta Airport is one of the Indonesian International airport located in the city of Tangerang with the top 20 busiest from 2010 to 2017 in the world, the area of facilities supporting the activities of Soekarno Hatta Airport which is set on Plan layout of Tangerang City area and plan Detail layout of urban area airport.The airport support area is an area that has facilities that directly and indirectly support airport activities, such as air aircraft workshop facilities, warehousing, sports, lodging, shops, restaurants, Golf courses, green open spaces, parking, leisure, and offices.But the Area that has been designated as a supporting facility does not work properly and maximally, so it needs to be rearranged to function properly. The authors use 5 methods of analysis, namely policy analysis, best practice, Location \& site, market, and the need for space to produce a proposal to plan the arrangement of area facilities supporting Soekarno Hatta Airport with an Airport Oriented approach Activities.
\end{abstract}

Keywords: Airport Oriented Activities; area of supporting facilities; airports; structuring plan

\section{PENDAHULUAN}

Indonesia merupakan negara kepulauan, memiliki lebih dari 17.000 pulau oleh karena itu Indonesia juga memiliki tingkat mobilitas yang sangat tinggi terutama pada bidang penerbangan dibandingkan dengan negara lain terutama yang bukan merupakan negara kepulauan. Indonesia memiliki banyak bandar udara yang tersebar diberbagai provinsi sebagai prasarana penerbangan, salah satunya terdapat pada Kecamatan Benda, Kota Tangerang, Provinsi Banten yaitu Bandara Internasional Soekarno Hatta. Bandara Internasional Soekarno Hatta telah menjadi bandar udara tesibuk 20 besar sejak tahun 2010 hingga tahun 2017 karena selalu memiliki jumlah penumpang yang sangat tinggi. 
Menurut data Airports Council International (ACI) passanger traffic 2016 final (annual) tanggal 1 January 2018 Bandara Soekarno Hatta termasuk dalam 20 besar tersibuk di dunia dengan jumlah penumpang sebanyak 58 juta penumpang. Oleh karena itu, pengembangan dari Bandara Internasional Soekarno Hatta sangat dibutuhkan mulai dari infrastruktur hingga fasilitas utama seperti terminal penerbangan yang hingga saat ini masih terus dikembangkan untuk menunjang kebutuhan dari pengguna jasa penerbangan Bandara Internasional Soekarno Hatta. Fasilitas penunjang sekitar Bandara juga perlu diperhatikan mengingat pengguna jasa penerbangan sebagian besar merupakan para pebisnis atau pejabat penting suatu daerah atau negara bukan hanya orang-orang yang pergi berlibur, maka dari itu dibutuhkan fasilitas penunjang yang berada disekitar bandar udara.

Menurut peta Rencana Tata Ruang Wilayah Kota Tangerang memang seharusnya kawasan sekitar bandar udara menjadi kawasan peruntukan fasilitas penunjang bandara dan dengan tingginya mobilitas pada Bandara Internasional Soekarno Hatta sangat memungkinkan untuk mengembangkan kawasan sekitar menjadi kawasan fasiltas penunjang bandara. Potensi tersebut juga akan menciptakan kawasan mandiri dengan bandara sebagai pusatnya yang kemudian disebut sebagai airport city. Hal inilah yang membuat penulis ingin mengembangkan kawasan Bandara Internasional Soekarno Hatta.

Masalah yang teridentifikasi pada objek studi area Bandara Soekarno Hatta yaitu: area yang merupakan fasilitas penunjang bandar udara masih belum berfungsi sepenuhnya, pembangunan infrastruktur tanpa diikuti dengan pembangunan fasilitas penunjangnya, dan status hak tanah pada objek studi sebagian besar masih berupa hak milik. Maksud dari penelitian ini adalah untuk membuat rencana penataan area Bandara Soekarno Hatta sebagai area fasilitas penunjang Bandara Soekarno Hatta.

Tujuan Umum penelitian ini adalah untuk membuat rencana penataan area Bandara Soekarno Hatta sebagai pendukung aktivitas bandar udara dengan pendekatan Airport Oriented Activities. Sedangkan tujuan khusus penilitian ini yaitu: mengetahui potensi objek studi sebagai area fasilitas penunjang aktivitas Bandara Soekarno Hatta, membuat usulan rencana penataan area Bandara Soekarno Hatta dengan pendekatan Airport Oriented Activities. Batasan substansial pada penelitian ini adalah mengenai pembuatan usulan rencana penataan area Bandara Soekarno Hatta dengan substansi aspek sebagai area fasilitas pendukung bandar udara dan dengan pendekatan Airport Oriented Activities. Batasan geografis penelitian ini adalah area Bandara Soekarno Hatta yang direncanakan pada Rencana Tata Ruang Wilayah Kota Tangerang sebagai area fasilitas pendukung bandar udara. Terletak pada kecamatan Benda. Dengan Batasan wilayah perencanaannya yaitu seluas $212 \mathrm{Ha}$. Batasan wilayah perencanaan dapat dilihat dibawah ini:

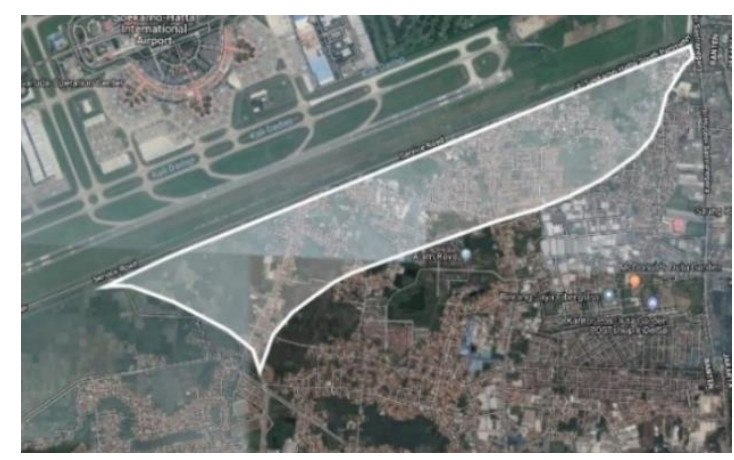

Gambar 1. Batasan Wilayah Rencana Penataan Area Fasilitas Bandara Soekarno Hatta Sumber: www.google.com/maps/

Metodologi penetapan deleniasi geografis yang digunakan untuk menentukan objek studi berdasarkan fungsi zona peruntukan fasilitas penunjang bandar udara yang telah ditetapkan dan tertera pada Peta Rencana Tata Ruang Wilayah Kota Tangerang tahun 2012-2032, Rencana 
Detail Tata Ruang Bagian Wilayah Perkotaan Bandara DSK tahun 2014-2034, dan juga berdasarkan Peta Rencana Sistem Jaringan Transportasi Kota Tangerang tahun 2012-2032. Dari peta tersebut maka ditetapkanlah batas objek studi.

\section{KAJIAN LITERATUR}

Bandar udara merupakan suatu fasilitas sebagai perantara (interface) antara transportasi udara dengan transportasi darat, yang secara umum fungsinya sama dengan terminal, yakni sebagai: tempat pelayanan bagi keberangkatan/kedatangan pesawat, untuk bongkar/muat barang atau naik/turun penumpang, tempat perpindahan (interchange) antar moda transportasi uadara dengan moda transportasi yang sama (transit) atau dengan moda transportasi yang lainnya, tempat klasifikasi barang/penumpang menurut jenis, tujuan perjalanan, dll, tempat untuk penyimpanan selama proses pengurusan dokumen, sebagai tempat untuk pengisian bahan bakar, perawatan dan pemeriksaan kondisi pesawat sebelum dinyatakan layak untuk terbang.

Kawasan penunjang bandar udara adalah kawasan yang diperuntukan bagi fasilitas yang secara langsung dan tidak langsung menunjang kegiatan bandar udara dan memberikan nilai tambah secara ekonomis pada penyelenggaraan bandar udara. Adapun arah dan fungsi pengembangan pada area ini meliputi: fasilitas perbengkelan pesawat udara, fasiltas pergudangan, fasilitas olah raga, penginapan, toko, restoran, lapangan golf, ruang terbuka hijau, perparkiran, rekreasi, dan perkantoran. Fungsi tersebut diperbolehkan dengan syarat meliputi industri non polutan dan fasiltas umum dan sosial berdasarkan ketentuan KKOP, kawasan kebisingan dan peraturan terkait penerbangan yang telah ditetapkan. Intensitas pemanfaatan ruang kawasan penunjang bandar udara meliputi: KDB maksimum $50 \%$ (lima puluh persen); KLB maksimum 4 (empat); tinggi bangunan maksimum sesuai dengan ketentuan dalam KKOP yang telah ditetapkan, KDH minimum $20 \%$ (dua puluh persen). Serta intensitas pemanfaatan ruang pada kawasan peruntukan penunjang bandar udara yang berada pada kawasan kemungkinan bahaya kecelakaan yang terletak di Kelurahan Neglasari, Kelurahan Mekarsari, Kelurahan Selapajang, Kelurahan Kedaung Wetan, Kelurahan Kedaung Baru Kecamatan Neglasari dan Kelurahan Benda Kecamatan Benda berlaku ketentuan sebagai berikut: KDB maksimum 40 \% (empat puluh persen); KLB maksimum 1,6 (satu koma enam); tinggi bangunan maksimum sesuai dengan ketentuan dalam KKOP yang telah ditetapkan, KDH minimum $20 \%$ (dua puluh persen). Fungsi yang tidak diperbolehkan meliputi perumahan, sekolah, dan rumah sakit.

Airport City Drivers Bandara telah berevolusi dengan bentuk spasial yang berbeda didasarkan pada lahan yang tersedia dan prasarana transportasi darat, namun hampir semua muncul sebagai tanggapan terhadap empat pendorong pembangunan yang menjadi pertimbangan utama. Keempat airport city driver tersebut adalah: bandara-bandara perlu menciptakan sumber daya dari kegiatan yang tidak berkaitan dengan penerbangan, untuk bersaing dan juga memberikan pelayanan yang lebih baik dari fungsi bandara, usaha sector komersial untuk mendapatkan lahan yang aksesibel, bandara mampu meningkatkan penumpang dan barang, pelayanan bandara sebagai katalis dan magnet untuk pembangunan kegiatan bisnis. Fasilitas di dalam Kota Bandara umumnya, meliputi: pertokoan, restoran, kegiatan entertainmen dan kebudayaan, hotel dan akomodasinya, bank dan penukaran mata uang asing, gedung Perkantoran, convention and exhibition centers, hiburan, rekreasi dan pusat kebugaran, logistik dan distribusi, pengawetan makanan dan pendinginan, katering dan kuliner, perdagangan bebas dan sejenisnya, lapangan golf, factory outlets, pelayanan keluarga, seperti klinik kesehatan dan penitipan anak. Kerangka kerja yang berguna untuk mengklasifikasikan aktivitas aeronautika dan non-aeronautika di dan sekitar bandara terbagi atas tiga kategori kegiatan berdasarkan sejauh mana mereka terkait dengan lalu lintas udara: Aktivitas inti penerbangan, operasional teknis dari bandara yang secara langsung mendukung fungsi-fungsi penerbangan (semua kegiatan bandara, jasa pengiriman barang kilat, perbelanjaan, hotel dan bongkar muat). Aktivitas yang berhubungan dengan Bandar udara 
merupakan kegiatan yang berhubungan dengan pengangkutan serta pergerakan penumpang dan barang (kawasan logistic dan perdagangan bebas, pusat kegiatan distribusi, pusat intermoda angkutan, kereta api). Aktivitas yang berorientasi pada Bandar udara memilih berada di area sekitar bandara dikarenakan imej yang dimiliki oleh bandara itu sendiri dan aksesibilitas jalan yang sangat baik. Harga lahan dan konektivitas yang baik merupakan faktorfaktor yang dipertimbangkan dalam pemilihan lokasi dari kegiatan-kegiatan tersebut (pusat perdagangan dan niaga grosir, convention center, pusat penelitian/teknologi, kawasan kesehatan, kawasan industri, mixed use, kawasan komersial, kawasan olah raga dan kawasan perkantoran).

\section{METODE}

Dalam proses pengumpulan data dibutuhkan beberapa metode pengumpulan data yang sesuai dengan kebutuhan yang meliputi jenis data dan Teknik pengumpulan data. Metode penelitian menggunakan metode deskriptif dengan pendekatan kualitatif, yaitu melakukan interview/wawancara dengan pihak Angkasa Pura II untuk mengetahui preferensi kebutuhan dari Bandara Soekarno Hatta.

Penelitian ini terdapat dua jenis data yaitu data primer dan data sekunder, antara lain sebagai berikut:

a) Data Primer

Data primer merupakan data yang didapat langsung dari objek penelitian seperti kondisi eksisting dan pengambilan foto. Jenis data primer yang diperlukan sebagai berikut:

1. Kondisi fisik eksisting area Bandara Soekarno Hatta

2. Penggunaan lahan eksisting area Bandara Soekarno Hatta

3. Melakukan wawancara kepada pihak instansi terkait

b) Data Sekunder

Data sekunder merupakan data yang didapatkan dari berbagai sumber yang relevan seperti buku, jurnal, dokumen-dokumen pemerintah serta sumber dari internet yang dapat dipertanggungjawabkan. Data sekunder yang diperoleh adalah sebagai berikut:

1. Peraturan kebijakan terkait fasilitas pendukung bandar udara

2. Masterplan rencana pengembangan Bandara Soekarno Hatta

3. RTRW Kabupaten, Kota Tangerang dan RDTR Kota Tangerang

4. Data Makro Kota Tangerang

5. Pendekatan Aerotropolis termasuk di dalamnya Airport City dan Airport

\section{Oriented Activities}

\section{Benchmarking}

7. Teori (Kajian Pustaka)

Dalam melakukan pengumpulan data dilakukan agar mendapatkan data mengenai objek studi. Dalam hal ini adalah Area Bandara Soekarno Hatta, maka dari itu diperlukan metode pengumpulan data yang sesuai dengan kebutuhan. Maka diperlukan teknik pengumpulan data dengan cara sebagai berikut:

a) Teknik Pengumpulan Data Primer

Data primer merupakan teknik perolehan data yang dilakukan secara langsung terhadap objek studi. Data yang diperoleh dapat berupa kuantitatif dan kualitatif yang bergantung pada kebutuhan peneliti. Pengumpulan data primer dilakukan pada saaat eksisting tahun 2018 dan 2019, dengan beberapa metode pengumpulan data, yaitu:

1. Survei Lapangan

Survei lapangan merupakan metode pengamatan langsung pada objek penelitian yang dilakukan oleh peneliti untuk mendapatkan data yang tidak bisa didapatkan dengan cara sekunder. Survei lapangan ini bertujuan untuk mengetahui kondisi lapangan eksisting dari objek yang akan diteliti.

2. Wawancara 
Wawancara merupakan metode pengambilan data melalui pertanyaan yang diajukan secara lisan dengan pihak terkait yaitu Dinas Pekerjaan Umum dan Penataan Ruang Kota Tangerang, Airport Learning Center, Airport Construction Division.

b) Teknik Pengumpulan Data Sekunder

Data ini diperoleh dari sumber lain terkait objek studi. Dalam penelitian ini data sekunder diperoleh dari berbagai sumber media yang relevan sehingga data diperoleh secara tidak langsung. Media data yang dimaksud adalah berupa media cetak dan elektronik, serta institusi yang terkait dengan objek studi. Pengumpulan data sekunder dapat diperoleh melalui beberapa media antara lain:

1. Instansi Terkait

Instansi pemerintah dan instansi swasta seperti Angkasa Pura II yang memiliki datadata terkait untuk keperluan studi. Berikut keperluan data adalah data makro dari Kota Tangerang, kebijakan, hak kepemilikan , dan lain sebagainya yang berhubungan dengan informasi objek studi.

2. Media Elektronik

Media elektronik digunakan untuk memperoleh informasi terkait yang berfungsi untuk melengkapi informasi sebagai gambaran dan juga dalam melakukan analisa. Bentuk penggunaan media eletronik yang dimanfaatkan adalah internet untuk memperoleh berita, peta, literature, tesis, dan hasil studi terkait lainnya.

\section{DISKUSI DAN HASIL}

Kota Tangerang merupakan kota terbesar Provinsi Banten dan disahkan berdasarkan hukum sejak tahun 1993 menurut uu no.2/1993. Kota Tangerang memiliki luas $164,54 \mathrm{~km}^{2}$ dan terdiri dari 13 kecamatan serta 104 kelurahan. Kota Tangerang merupakan kota terbesar ketiga di kawasan Jabodetabek setelah Jakarta dan Kota Bekasi. Secara astronomis Kota Tangerang terletak pada posisi 10636' - 10642' Bujur Timur dan 66' - 613' Lintang Selatan, lokasinya juga strategis karena berada di antara Ibukota Negara DKI Jakarta dan Kabupaten Tangerang. Sesuai dengan Instruksi Presiden Nomor 13 Tahun 1976 tentang Pengembangan Jabotabek (Jakarta, Bogor, Tangerang, Bekasi), Kota Tangerang merupakan salah satu daerah penyangga Ibukota Negara DKI Jakarta.

Kota Tangerang memiliki aksesibilitas yang baik dengan sistem jaringan transportasi terpadu kawasan Jabodetabek dan simpul transportasi berskala nasional dan internasional, seperti Bandara Internasional Soekarno-Hatta, Pelabuhan Internasional Tanjung Priok, Pelabuhan Merak serta Pelabuhan Bojonegara serta jalur transportasi darat yang sangat baik dengan dilaluinya oleh Jalan tol Jakarta-Tangerang dan Jalan-jalan arteri yang dapat diakses dengan mudah terutama oleh kawasan Jabodebek. Dalam dokumen Rencana Tata Ruang Kota Tangerang Tahun 2012-2032, Bandara Soekarno Hatta termasuk ke dalam:
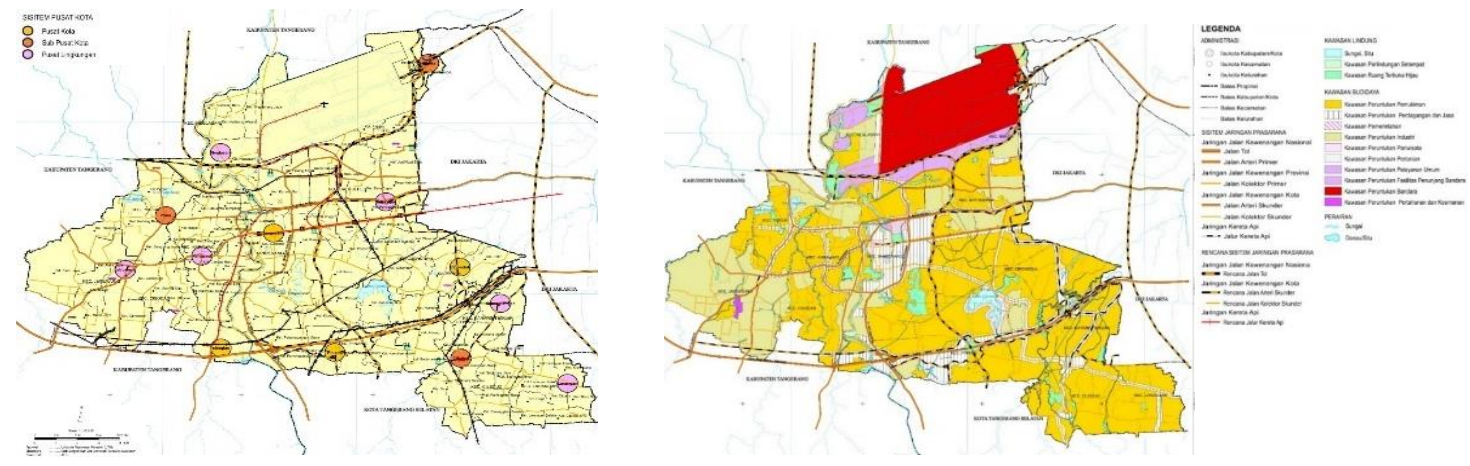

Gambar 2. Peta Rencana Struktur dan Pola Ruang Kota Tangerang Sumber: RTRW Kota Tangerang Tahun 2012-2032 
Berdasarkan Rencana Struktur Kota Tangerang dan Pola Ruang Kota Tangerang, Bandara Soekarno Hatta termasuk ke dalam sistem sub pelayanan pusat kota dengan rencana kawasan pusat pelayanan ekonomi, sosial dan/atau administrasi yang melayani sub wilayah kota berupa kegiatan pemerintahan, perdagangan dan jasa skala kota, dan ruang terbuka hijau dengan penyesuaian ketentuan KKOP. Peruntukan kawasan di sekitar Bandara Soekarno Hatta yang termasuk ke dalam Kota Tangerang memiliki zona peruntukan sebagai kawasan fasilitas penunjang bandar udara. Area Bandara Soekarno Hatta yang menjadi objek studi sebagai rencana penatanaan fasilitas penunjang bandar udara termasuk kedalam administrasi Kecamatan Benda, di bawah ini akan dijelaskan lebih detail mengenai legalitas, rencana detail tata ruang, dan aksesibilitas sekitar area fasilitas penunjang Bandara Soekarno Hatta sebagai objek studi perencanaan.

Berdasarkan peta hak kepemilikan lahan dari badan pertanahan nasional pada objek studi terdeleniasi, terlihat bahwa terdapat 3 jenis hak kepemilikan yaitu hak milik, hak guna bangunan, tidak terdaftar dan sisanya adalah tidak memilikistatus apa-apa. Sebagian besar didominasi oleh status hak milik, tidak memiliki status, hak guna banguanan, dan tidak terdaftar. Dalam dokumen Rencana Detail Tata Ruang Bagian Wilayah Perkotaan Bandara Tahun 2014-2034, objek studi termasuk ke dalam:

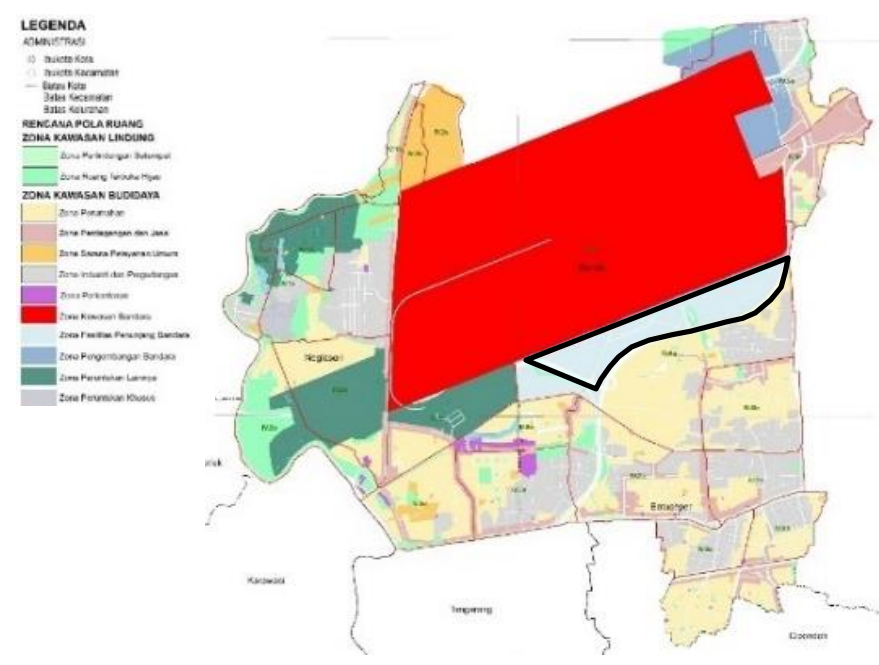

Gambar 3. Peta Rencana Detail Tata Ruang Bagian Wilayah Perkotaan Bandara Sumber: RDTR Bagian Wilayah Perkotaan Bandara Tahun 2014-2034

Berdasarkan Rencana Detail Tata Ruang Bagian Wilayah Perkotaan Bandara, objek studi memiliki peruntukan yaitu sebagai zona fasilitas penunjang bandara (Kecamatan Benda) sedangkan berbeda dengan area peruntukan fasilitas penunjang bandara di Kecamatan Neglasari berubah menjadi zona peruntukan lainnya ketika sudah didetailkan pada RDTR BWP Bandara. Objek Studi memiliki aksesibilitas yang cukup baik, dapat diakses melalui Jalan Husein Sastranegara yaitu jalan arteri dengan status kota dengan ROW jalan sebesar 17 meter. Area objek studi berada tepat disebelah selatan Bandara Soekarno Hatta membuat aksesibilitas kedepannya semakin mudah dan baik seiring dengan dibangunnya infrastuktur jaringan jalan dan moda transportasi seperti jalan tol JORR2 dan juga moda kereta api bandara yang melintasi area objek studi. Transportasi umum yang melintasi area objek studi adalah:

- Angkot B95 dan B09A dengan Rute: Cikokol - Halte Yuppentek - Jl. Daan Mogot - JL. Pembangunan 3 - JL. Halim Perdana Kusuma - JL. Husein Sastranegara - JL. Perancis JL. Raya Dadap - Dadap.

- Kereta Bandara Soekarno Hatta dengan Rute: Stasiun Manggarai - BNI City - Sudirman Baru - Duri - Batu Ceper - Bandara Soekarno Hatta. 
- Jalan Tol JORR 2: Proyek Jalan Tol akses Tanjung Priok, Cibitung-Cilincing, CimanggisCibitung, Cinere-Jagorawi, Depok-Antasari, Serpong-Cinere, Kunciran-Serpong, Cengkareng-Kunciran.

Untuk mendapatkan hasil usulan rencana penataan area fasilitas penunjang Bandara diperlukan 5 analisis yaitu analisis kebijakan, analisis best practice, analisis lokasi \& tapak, analisis pasar, dan analisis kebutuhan ruang. Hasil dari analisis kebijakan dapat disimpulkan bahwa batasan dari penataan area objek studi yang dapat menunjang kegiatan bandara adalah:

a. Objek studi merupakan zona peruntukan fasilitas penunjang bandar udara yang ditetapkan sebagai kawasan budi daya prioritas.

b. Fasilitas yang tersedia bersifat secara langsung/tidak langsung mendukung kegiatan Bandara Soekarno Hatta meliputi pusat pelayanan ekonomi, sosial, dan administratif.

c. Objek studi terletak di Kecamatan Benda merupakan kawasan dengan kebisingan tingkat (2) yaitu tanah dan ruang udara yang dapat dimanfaatkan untuk berbagai jenis kegiatan kecuali untuk jenis bangunan sekolah, rumah sakit, dan rumah tinggal.

d. Arah dan fungsi pengembangan pada area ini meliputi: fasilitas perbengkelan pesawat udara, pergudangan, olah raga, penginapan, toko, restoran, lapangan golf, ruang terbuka hijau, perparkiran, rekreasi, perkantoran.

e. Fungsi tersebut diperbolehkan dengan syarat meliputi industri non polutan dan fasiltas umum dan sosial berdasarkan ketentuan KKOP, kawasan kebisingan dan peraturan terkait penerbangan yang telah ditetapkan.

f. Ketentuan intensitas yang diperbolehkan pada area objek studi yang berada di Kecamatan Benda sebagai berikut:

- KDB maksimum $40 \%$ (empat puluh persen);

- KLB maksimum 1,6 (satu koma enam);

- Tinggi bangunan maksimum sesuai dengan ketentuan dalam KKOP yang telah ditetapkan yaitu kawasan di bawah permukaan horizontal-dalam dengan tinggi maksimal adalah 46 meter.

- $\mathrm{KDH}$ minimum $20 \%$ (dua puluh persen).

Hasil dari analisis best practice dapat disimpulkan bahwa fasilitas yang akan diterapkan dari kunci kesuksesan benchmark Changi International Airport dan Inchoen International Airport ditinjau dari kebijakan, kelebihan, kekurangan dan pendekatan yang dilakukan adalah fasilitas penunjang: gudang cross docking/transit, industri ringan, restoran, bank center, hotel transit, perkantoran tematik, ruang terbuka hijau, taman tropis, convention center, dan hunian. Pergudangan cross docking/transit adalah gudang yang diperuntukan untuk penyedia jasa ekspedisi sebagai tempat pemindahan barang yang digabungkan untuk tujuan pengiriman yang sama lalu diberangkatkan dengan waktu secepatnya tanpa harus disimpan di dalam Gudang. Industri ringan adalah industri yang menghasilkan barang siap pakai/konsumsi. Taman tropis/bali adalah perpaduan dari kombinasi berbagai tanaman tropis serta pernik dan aksesoris tradisional yang memiliki unsur etnik bali. Hotel transit adalah hotel dengan fasilitas penginapan yang bisa disewa oleh orang yang memiliki tujuan bisnis/transit dengan waktu relatif singkat seperti 1 hari, 12 jam, dan bahkan 6 jam. Perkantoran tematik adalah perkantoran tipikal dengan tema tertentu dengan luas yang cukup besar dengan tinggi bangunan berkisar antara 2-3 lantai. Hasil dari analisis lokasi \& tapak dapat disimpulkan dengan menggunakan tabel S.W.O.T sebagai berikut: 
Tabel 1. S.W.O.T (Strength, Weakness, Opportunity, Threats)

\begin{tabular}{|c|c|c|}
\hline \multirow[b]{2}{*}{ SWOT } & Strength: & Weakness: \\
\hline & $\begin{array}{l}\text {-Lahan berada tepat di } \\
\text { selatan Bandara Soekarno } \\
\text { Hatta } \\
\text {-Terdapat Gate Tol H. } \\
\text { Sastranegara pada lahan } \\
\text {-Memiliki akses langsung } \\
\text { menuju Bandara Soekarno } \\
\text { Hatta } \\
\text {-Tingkat intensitas yang } \\
\text { tidak terlalu tinggi dan } \\
\text { masih didominasi oleh } \\
\text { lahan pertanian. }\end{array}$ & $\begin{array}{l}\text {-Jaringan jalan dalam area objek studi } \\
\text { masih buruk } \\
\text {-Terdapat polusi kebisingan tingkat } 2 \\
\text { akibat aktivitas penerbangan } \\
\text {-Peruntukan selain fasilitas penunjang } \\
\text { bandara lebih mendominasi } \\
\text {-Tanah pada objek studi sebagian besar } \\
\text { memiliki status hak milik }\end{array}$ \\
\hline unity: & S-O: & W-O: \\
\hline $\begin{array}{l}\text {-Objek studi telah } \\
\text { ditetapkan oleh Perda Kota } \\
\text { Tangerang No. } 6 \text { Tahun } \\
2012 \text { sebagai kawasan budi } \\
\text { daya prioritas } \\
\text {-Memiliki aksesibilitas yang } \\
\text { baik karena mendapat akses } \\
\text { langsung dari Jalan Tol JORR } \\
2 \text { dan Jalan Husein } \\
\text { Sastranegara (jalan arteri) }\end{array}$ & $\begin{array}{l}\text {-Objek studi menjadi area } \\
\text { fasilitas penunjang } \\
\text { Bandara Soekarno Hatta } \\
\text { dengan akses dan } \\
\text { keterdekatan yang baik } \\
\text {-Mendapat dukungan dari } \\
\text { pihak pemerintah dan } \\
\text { swasta karena objek studi } \\
\text { merupakan kawasan } \\
\text { prioritas }\end{array}$ & $\begin{array}{l}\text {-Membuat rencana penataan dengan } \\
\text { sistem jaringan jalan yang baik } \\
\text {-Membuat layer berupa RTH pada } \\
\text { daerah perbatasan Bandara } \\
\text {-Memaksimalkan penataan fasilitas } \\
\text { dengan fusngsi yang dapat menunjang } \\
\text { Bandara Soekarno Hatta } \\
\text {-Karena merupakan kawasan prioritas } \\
\text { dengan peruntukan yang detail tentang } \\
\text { fasilitas penunjang, maka tanah dapat } \\
\text { diusahakan untuk dibebaskan }\end{array}$ \\
\hline Threats: & $\mathrm{S}-\mathrm{T}:$ & $\mathrm{W}-\mathrm{T}$ : \\
\hline $\begin{array}{l}\text {-Angkutan umum yang } \\
\text { tersedia sangat terbatas } \\
\text {-Daerah sekitar objek studi } \\
\text { yang berada di Kecamatan } \\
\text { Benda merupakan daerah } \\
\text { rawan banjir, terutama } \\
\text { Kelurahan Jurmudi baru }\end{array}$ & 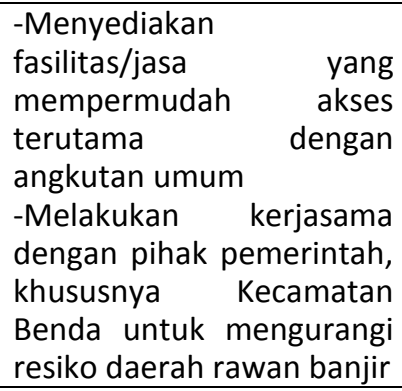 & $\begin{array}{l}\text {-Memperbesar RTH untuk mengurangi } \\
\text { tingkat kebisingan yang ada } \\
\text {-Menambahkan fasilitas-fasilitas dengan } \\
\text { peruntukan yang sesuai } \\
\text {-Membuat penataan yang bertahap }\end{array}$ \\
\hline
\end{tabular}

Sumber: Penulis, 2019

Hasil dari analisis pasar dan analisis kebutuhan ruang dapat disimpulkan bahwa pembagian zona fasilitas dan kebutuhan untuk setiap jenis fasilitas adalah sebagai berikut:

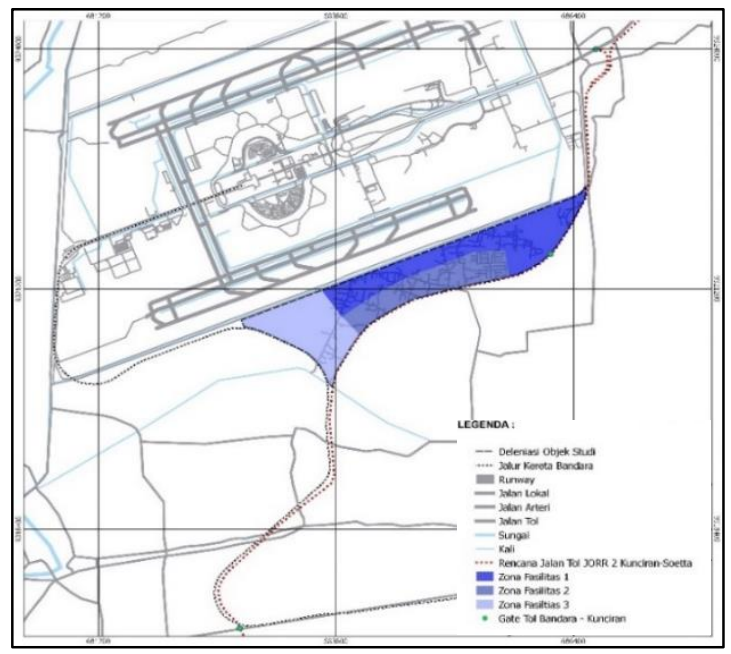

Gambar 4. Peta Pembagian Zona Fasilitas Sumber: Penulis, 2019 
Tabel 2. Kebutuhan Ruang Pada Zona 1-3

\begin{tabular}{|c|c|c|c|c|c|}
\hline & Luas Efektif & & $59.7 \%$ & 126.6 ha & \\
\hline Zona & Fasilitas & Luas $\left(\mathrm{m}^{2}\right)$ & Unit & Total Luas (ha) & Persentase \\
\hline \multirow{2}{*}{1} & Gudang Transit & 2,172 & 182 & 39.5 & $69.3 \%$ \\
\hline & Industri Ringan & 2,500 & 70 & 17.5 & $30.7 \%$ \\
\hline \multicolumn{2}{|l|}{ Total } & & & 57 & \\
\hline \multicolumn{2}{|c|}{ Site Coverage } & & & & $100 \%$ \\
\hline \multirow{2}{*}{2} & Hunian & 180 & 1,230 & 22.14 & $67.1 \%$ \\
\hline & Hunian Eksisting & - & - & 10.86 & $32.9 \%$ \\
\hline \multicolumn{2}{|l|}{ Total } & & & 33 & \\
\hline \multicolumn{2}{|c|}{ Site Coverage } & & & & $100 \%$ \\
\hline \multirow{6}{*}{3} & Hotel Transit & 4,050 & 26 & 10.53 & $29.25 \%$ \\
\hline & \multirow{2}{*}{ Convention Center } & 3,750 & 2 & 0.75 & $2.1 \%$ \\
\hline & & 30,000 & 2 & 6 & $16.6 \%$ \\
\hline & Restoran & 675 & 43 & 2.9 & $8.1 \%$ \\
\hline & Bank Center & 600 & 7 & 0.42 & $1.1 \%$ \\
\hline & Perkantoran Tematik & 750 & 200 & 15 & $41.7 \%$ \\
\hline \multicolumn{2}{|l|}{ Total } & & & 35.6 & \\
\hline \multicolumn{2}{|c|}{ Site Coverage } & & & & $98.83 \%$ \\
\hline \multicolumn{2}{|r|}{ Luas Non-Efektif } & & $40.3 \%$ & 85.4 ha & \\
\hline Zona & Fasilitas & Luas $\left(\mathrm{m}^{2}\right)$ & Unit & Total Luas (ha) & Persentase \\
\hline 1 & Ruang Terbuka Hijau & & & 19.78 & $23.2 \%$ \\
\hline \multirow{2}{*}{2} & Taman & 2,400 & 2 & 5.5 & $6.4 \%$ \\
\hline & Taman & & & 3.1 & $3.6 \%$ \\
\hline \multirow[t]{3}{*}{3} & Ruang Terbuka Hijau & & & 10.9 & $12.8 \%$ \\
\hline & Jalan & & & 41.85 & $49 \%$ \\
\hline & Prasarana & & & 4.27 & $5 \%$ \\
\hline \multicolumn{2}{|l|}{ Total } & & & 85.4 & \\
\hline \multicolumn{2}{|c|}{ Site Coverage } & & & & $100 \%$ \\
\hline
\end{tabular}

Dari 5 analisis tersebut, didapat konsep dan recana dari penataan area fasilitas penunjang Bandara Soekarno Hatta sebagai berikut:

Tabel 3. Rencana Penataan Area Fasilitas Penunjang Bandara Soekarno Hatta

Rencana Arahan

Pengadaan dan peningkatan Fasilitas penunjang yang akan ditambahkan yaitu gudang kuantitas serta kualitas fasilitas transit, industri ringan, townhouse, hotel transit, convention penunjang bandar udara center, expo hall, restoran, bank center, perkantoran tematik, taman, dan ruang terbuka hijau menggunakan pendekatan Airport Oriented Activities dan batasan dari kawasan fasilitas penunjang bandar udara.

Pengadaan dan peningkatan Infrastuktur dan prasarana yang akan ditambahkan dan kualitas serta kuantitas ditingkatkan kualitasnya adalah pengadaan jalan baru, yaitu infrastruktur \& prasarana jalan kolektor, jalan lokal utama, dan jalan lokal. Prasarana air bersih, persampahan, listrik, pembuangan air kotor

Penataan zonasi Pembagian zonasi area fasilitas penunjang Bandara Soekarno Hatta menjadi 3 zona, yaitu zona industri dan pergudangan, zona perkantoran, perdagangan dan jasa, zona perumahan. 


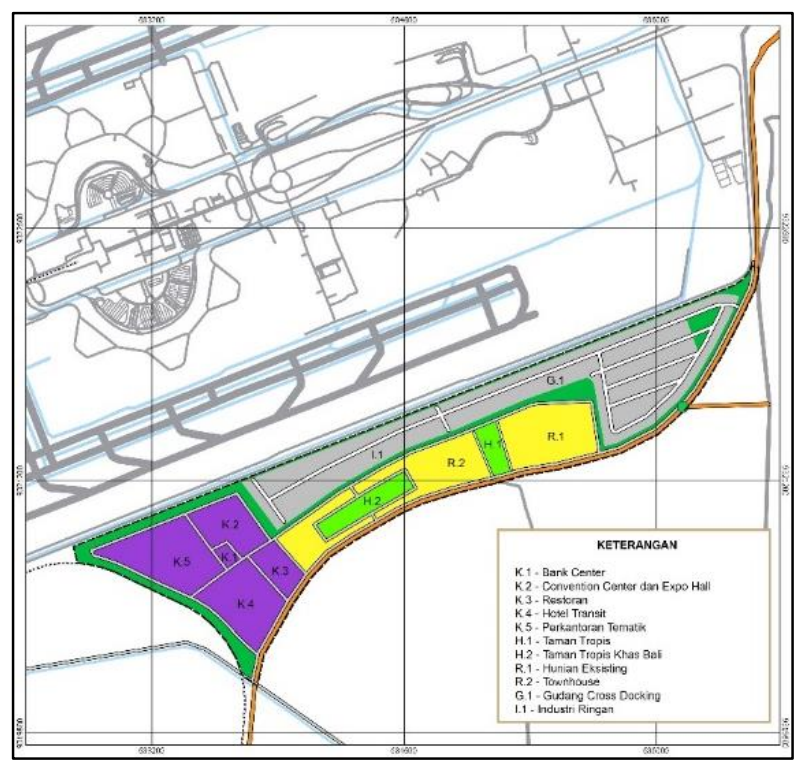

Gambar 5. Masterplan Area Fasilitas Penunjang Bandara Soekarno Hatta Tahun 2030 Sumber: Penulis, 2019

\section{KESIMPULAN DAN SARAN}

Kesimpulan dari penelitian yang dilakukan untuk rencana penataan area fasilitas penunjang Bandara Soekarno Hatta adalah sebagai berikut:

a. Objek studi memiliki lokasi yang cukup strategis, luas area yang cukup besar, dan aksesibilitas yang baik dengan terhubungnya dengan Jalan Tol JORR 2 Kunciran-Bandara dan Jalan Arteri Husein Sastranegara sebagai area fasilitas penunjang bandar udara, yaitu Bandara Soekarno Hatta.

b. Objek studi termasuk kedalam zona peruntukan fasilitas penunjang bandar udara yang ditetapkan sebagai kawasan budi daya prioritas menurut Rencana Tata Ruang Wilayah Kota Tangerang dan rencana Detail Tata Ruang Bagian Wilayah Perkotaan Bandara. Oleh karena itu objek studi juga memiliki batasan dalam hal pengembangan dan penataannya dalam hal jenis fasilitas yang dapat dibangun, seperti fasilitas perbengkelan pesawat udara, fasiltas pergudangan, fasilitas olah raga, penginapan, toko, restoran, lapangan golf, ruang terbuka hijau, perparkiran, rekreasi, dan perkantoran.

c. Objek studi memiliki lokasi yang sangat dekat dengan Bandara Soekarno Hatta, yaitu di sisi sebelah selatan bandara yang membuat objek studi dalam hal rencana penataannya sangat terikat dengan peraturan intensitas dan isu-isu seperti isu kebisingan dan kasawan keselamatan operasional penerbangan.

d. Objek studi sebagai area fasilitas penunjang bandar udara saat ini masih belum maksimal karena belum difungsikan sebagaimana harusnya dalam segi sarana, prasarana, infrastruktur, dan penggunaan lahan. Sehingga membuat area objek studi tidak efektif dan efisien dalam hal menunjang kegiatan dari aktivitas Bandara Soekarno Hatta maupun penumpang dan pengguna jasa Bandara Soekarno Hatta.

e. Rencana penataan area objek studi sebagai fasilitas penunjang bandar udara menggunakan pendekatan Airport Oriented Activities yang merupakan salah satu dari 3 skematik desain utama dari konsep Aerotropolis. Dalam hal penataannya memiliki kendala terhadap status tanah yang terdapat $65.1 \%$ status hak milik.

f. Rencana penataan area fasilitas penunjang Bandara Soekarno Hatta dilakukan hingga proyeksi tahun 2030 dengan peningkatan penumpang sebanyak $\pm 70 \%$ dari penumpang tahun 2017. Dengan dilakukannya analisis kebijakan, best practice, lokasi \& tapak, pasar, dan kebutuhan ruang maka didapat fasilitas penunjang Bandara Soekarno Hatta yang dibutuhkan, yaitu gudang transit, industri ringan, hunian, townhouse, bank center, 
restoran, hotel transit, convention center, expo hall, taman, perkantoran tematik, dan ruang terbuka hijau dengan masing-masing kebutuhannya.

g. Rencana Penataan area fasilitas penunjang Bandara Soekarno Hatta terbagi atas 3 zona, yaitu zona 1: gudang transit dan industri ringan, zona 2: Hunian, townhouse, dan taman, zona 3: bank center, convention center, expo hall, restoran, hotel transit, dan perkantoran tematik. 5 tahap, yaitu tahap 1: gudang transit, industri ringan ( $50 \%$ dari total kebutuhan), dan hunian, tahap 2: townhouse dan taman, tahap 3: bank center, convention center \& expo hall, restoran, hotel transit, dan perkantoran tematik (60\% dari total kebutuhan), tahap 4: industri ringan ( $50 \%$ dari total kebutuhan), tahap 5: perkantoran ( $40 \%$ dari total kebutuhan).

Dari maksud, tujuan, dan penelitian yang telah dilakukan, didapatkan beberapa saran untuk area objek studi sebagai fasilitas penunjang bandar udara, yaitu:

a. Perlu dibuat rencana pengelolaan yang baik dari segi manajemen fasilitas, pengadaan event, dan juga sistem transportasi umum yang terintegrasi sehingga fungsi dari fasilitas penunjang bandar udara yang berada di objek studi tetap maksimal.

b. Perlu melibatkan masyarakat sekitar dalam hal mengelola fasilitas yang ada sehingga dapat menaikan kesejahteraan masyarakat sekitar dengan lapangan pekerjaan baru.

\section{REFERENSI}

Airports Council International. (2013). Special Reports: Airport Cities. Airport World.

Changi Airport Singapore. (2018). Jelajahi Changi: Fasilitas Changi. Retrieved from Changi Airport Singapore: https://id.changiairport.com

Gerhana, P. (2019). Jaringan Jalan Tol JORR 2 Kunciran - Bandara Soetta. (R. Suhardi, Interviewer)

Güller. (2001). From Airport to Airport City. Barcelona: Litogama.

Kasarda, J. D. (2008). The Evolution of Airport Cities dan Aerotropolis. London: Insight Media.

Kementrian Perhubungan. (2018). Rencana Induk Bandara. Tangerang.

Lubis, B. U. (2015). The Aerocity. The Future of Indonesian Airport, 28.

PT Angkasa Pura II Indonesia's Airport Company. (2018). Airport Grow Faster, Grow Beyond Core - Annual Report 2018. Indonesia: PT Angkasa Pura II (Persero).

Situs Resmi Pemerintah Kota Tangerang. (2007). Profil Kota: Geografi. Retrieved from Situs Resmi Pemerintah Kota Tangerang Web Site: tangerangkota.go.id

Zamanov, A. (2017). Airport City . Designing The Airport City: An International Perspective. Çankaya, Ankara, Turkey: METU Library E-Theses index. 
